Type of the Paper (Article, Review, Communication, etc.)

\title{
Impact of Battery Energy Storage System and its Converter Characteristics on Voltage Sags
}

\author{
Nhlanhla Mbuli 1, 2, ", Sebu Lichaba ${ }^{2}$, Ronald Xezile ${ }^{2}$ and Jan-Harm C Pretorius ${ }^{2}$ \\ 1 Eskom Holdings SoC Limited, ERIC, Lower Germiston Road, Rosherville, 2022, South Africa; \\ sebu.lichaba@eskom.co.za; xezilerm@eskom.co.za \\ 2 University of Johannesburg, corner Kingsway and University Road, Auckland Park, Johannesburg, 2006, \\ South Africa; jhcpretorius@uj.ac.za \\ * Correspondence: mbulin@eskom.co.za; Tel.: +27 11629 5115/5539
}

\begin{abstract}
Voltage sags can cause the interruption of power supply and can negatively affect operations of customers. In this paper, the authors study the impact of battery energy storage systems (BESS) on voltage sags. A stochastic method of fault positions is used. Faults of various types are simulated and voltages are recorded. Firstly, with the BESS integrated into the network, there are higher residual voltages, fewer voltage sags and less expected critical voltage loss. Secondly, if the BESS converter power factor is reduced, recorded residual voltages are higher, voltage sags are fewer, and the number of expected critical voltage sags is lower. Finally, when three BESS converter control modes, namely constant voltage, constant power factor, and constant reactive power, were assessed, results showed similar voltage sag performances for constant power factor and constant reactive power modes. Furthermore, operating in constant voltage control outperformed the other two modes as it resulted in higher residual voltages, a lower number of voltage sags, and fewer expected critical voltage sags. The paper has demonstrated that the BESS can improve voltage sag performance. In addition, the power factor of the BESS converter and the mode of operation of the converter can influence the magnitude of the voltage sag performance improvement.
\end{abstract}

Keywords: Battery energy storage system (BESS); method of fault positions; renewable energy; transient stability; voltage sags

\section{Introduction}

Electricity is a commodity that requires immediate consumption upon generation [1,2], otherwise it may be wasted or can cause instability in the power system. Alternatively, some mechanism of storing excess production, until it can be consumed, is required. Consequently, an energy storage system (ESS) is an integral part for economic power generation. Electrical energy from a power source can be stored in a number of forms or mediums, such as chemical, kinetic, gravitational potential energy, capacitors and magnetic fields.

Globally, some developments have led to a renewed interest in energy storage. Fossil fuels have been the main contributor to the generation of electrical power. However, concerns about [3] greenhouse gas emissions, the depletion of fossil fuel reserves, increasing oil prices, and security of energy have contributed to the increased focus on using renewable energy sources [RES] as these are clean and abundant [4]. This has led to a significant growth in globally installed RES generation from $814 \mathrm{GW}$ in 2004 to $1712 \mathrm{GW}$ in 2014 [5] and to $2378 \mathrm{GW}$ [6] in 2018. It could further reach $12061 \mathrm{GW}$ and $27016 \mathrm{GW}$ in 2030 and 2050 [7], respectively.

Despite the benefits they bring, the renewable energy [RE] generation does not come problem free. The primary RE resources $[8,9]$ are intermittent and stochastic in their availability, in the case of wind and solar, in particular, and they vary with the meteorology of the atmosphere [10]. This makes 
the generators non-dispatchable. The availability of the resource is also location constrained. Finally, the RE plants connect into the grid via inverter, i.e., non-synchronously. This leads to several challenges in the operation of the system [11,12] related to voltage rise, power quality, protection, stability, and maintaining the balance between generation and load.

Energy storage systems can ameliorate the challenges [13] caused by the variable renewable energy sources in the grid. Thus, as the use of VRES has been increasing and there has been a concomitant increase in the uptake of energy storage systems [ESS]. In the case of the battery energy storage system (BESS), the installed capacity grew from just under $100 \mathrm{MW}$ in 2000 to just over 600 MW in 2015 [14]. Some forecasts indicate that there will be a sharp growth in installed capacity to 18000 MW by 2023 [15].

Besides being able to address some of the challenges associated with VRES, BESS can also provide a suite of other services to the grid $[16,17]$, one of which is the ability to solve the quality of supply problems. Specifically, storage can protect customers [18] against short-duration events that affect the quality of the supply to customers.

A literature review of publications in which a BESS was used to solve voltage-related quality of supply issues was conducted. In the first batch of applications, both the active and reactive power of the BESS could be controlled. These include the investigation of the use of a BESS [19], by Yan et al., to compensate voltage flicker, a methodology for placement of a BESS, proposed by Cifuentes et al., to improve voltage stability in a network with high levels of converter-based generation technologies [20], and a proposed algorithm [21] by Ahmed et al. for optimal sizing and placement of a BESS to mitigate voltage sags and their consequences in a distribution system.

Tant et al. evaluated the use of a BESS in low voltage residential networks to maintain acceptable voltage regulation amidst increasing PV penetration levels [22]. A study by Rouco and Sigrist on how a BESS [23] can enhance voltage regulation in a weak network was characterised by low short circuit levels, and in [24], the performance of a BESS, supplying both $P$ and $Q$, a STATCOM, supplying $Q$, in restoring voltages in islanded microgrids are compared by Rabbi et al.

The second group of papers, evaluates the controlled charging/discharging of active power of a BESS for the improvement of some network objective. Jamroen et al. discuss a control strategy to absorb/inject $P$ from a BESS to limit voltage rise [25] in a low-voltage microgrid with high PV penetration, while Zeraati et al. [26] use a distributed control strategy based on charging/discharging a BESS to enhance voltage regulation in a low voltage network. Arduini et al. [27] demonstrate how charging and discharging a BESS can be used to regulate the power output of a Doubly-Fed Induction Generator (DFIG) connected to a medium voltage bus.

In [28], Kawabe and Yokoyama discuss a method of compensation based on injecting/absorbing $P$ from a BESS to improve the short-term voltage stability, in a network supplying induction motor load. The capability of discharging a BESS to support the voltages and provide loading relief to the system during undervoltage load shedding is assessed in [29] by Pereira et al.

A third group of papers use a BESS, in combination with some fast-acting, reactive power compensation device to achieve full independent active and reactive power control. A subset of this group assesses various BESS/ STATCOM schemes. This scheme is assessed by Yang et al. [30] for voltage regulation enhancement, by Ghorbanian et al. [31] for reducing the severity of voltage sags in a network with a DFIG, by Liu et al. [32] to alleviate the angle stability and ease voltage drop in a weak grid. Kanchanaharuthai et al. evaluate the ability of the scheme to enhance voltage regulation [33] in a large-scale multimachine power system with synchronous generators and DFIGs.

Another subset of papers focuses on a scheme utilising a BESS/DSTATCOM combination. Menaneanatra et al. [34] assess whether this scheme can enhance the low voltage fault ride-through capability of DFIG. In [35], Virulkar and Aware researched how this scheme can compensate for voltage flicker generated by an electric arc welder.

The literature above provides valuable insights into how the BESS, on its own or as part of an integrated BESS/FACTS scheme, has been studied in attempts to resolve voltage-related quality of supply problems. One of the manifestations of voltage problems is voltage sags which are caused by faults that can occur randomly across the entire power system. According to IEEE Standard 1159- 
1995 [36], voltage sag may be defined as a reduction in root means square voltage to between 0.1 and 0.9 per unit voltage, for durations in the 0.5 cycles to one-minute range. These sags are a major contributor to unwanted trips and lead to [37] costs, to both producers and consumers of electricity, associated with equipment damage and absence of electricity as a factor of production and consumption.

Some of the publications reviewed addressed how the control of the BESS active power, reactive or both, can be implemented to ameliorate sags. However, the studies tended to look at a fault occurring at a particular location and never considered the fact that faults leading to voltage sags actually do occur across the system. Thus, although the insight generated by these studies is valuable, more appreciation of how a BESS can deal with sags can be obtained by considering the system-wide occurrence of voltage sags. Also, from a perspective of system-wide voltage sags, none of the studies reported on the impact of the BESS power factor and mode of operation on voltage sags.

The aim of this paper is to study the impact of incorporating a BESS on voltage sags experienced at some monitoring bus. A stochastic approach will be utilised in the study and faults occurring across the entire power system will be considered. The specific objectives the study are:

- To assess the impact of incorporating a BESS on the severity of voltage sags initiated by faults experienced in the entire system.

- To study the impact of the power factor of the BESS converter output on the severity of voltage sags due to faults across the power system.

- To evaluate and compare the impacts of various BESS control modes, i.e., constant voltage control mode, constant power factor control mode and constant reactive power control mode on the severity of voltage sags.

To assess the severity of voltage sags, three aspects will be considered, namely, the magnitudes of residual voltages, the number of voltage sags observed, and the number of critical voltage sags counted for various levels of voltage sensitivity of equipment.

The remainder of the manuscript will comprise the following sections. In Section 2, an overview of a BESS and some of its operational issues are discussed. Section 3 discusses how the output of a BESS affects the voltage at a busbar. A stochastic approach for studying system-wide voltage sags is presented in Section 4. Section 5 discusses the methodology of the study, with the results presented in Section 6. Results are discussed in Section 7 and Conclusions are drawn in Section 8.

\section{Overview, Impacts on Bus Voltages and Modes of Operation of a BESS}

This section discusses $[25,26]$ the components of a BESS, how a BESS affects voltages of the grid bus to which the BESS feeds, and the various modes of operation of a BESS converter.

\subsection{Architecture of a BESS}

A typical BESS comprises the following components [38,39]:

- a direct current system: Here individual cells are arranged in modules, which, in turn, get assembled in systems that have adequate capacity to support applications of interest. Cells are arranged and connected in series and in parallel to power a high voltage bus.

- a power conversion system (PCS). This is a dc/ac current converter connecting the dc system to the grid via a transformer. The active and reactive power outputs of the converter are controlled (to supply or absorb these) independently, leading to a four-quadrant converter operation.

- the battery management system (BMS). The BESS may comprise several independent blocks, each made of a dc sub-system, PCS, and transformer. The BMS coordinates the operation of individual power blocks.

- a system supervisory control (SSC). The SSC is coordinating the operation of the all the power blocks, manages the total system power and also oversees the allotment of that power among the power blocks. 


\subsection{Impact of BESS on Voltages at a Point of Common Coupling}

Figure 1 shows a typical BESS feeding into the grid. Figure 1 (a) is a detailed circuit for the setup and the equivalent circuit included as Figure 1(b). The BESS is represented by a current source, and it injects current $I_{i}$ at the point of common coupling (PCC), i.e., at bus $i$.

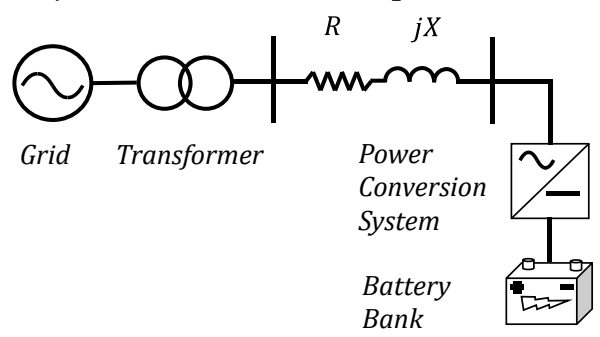

(a)

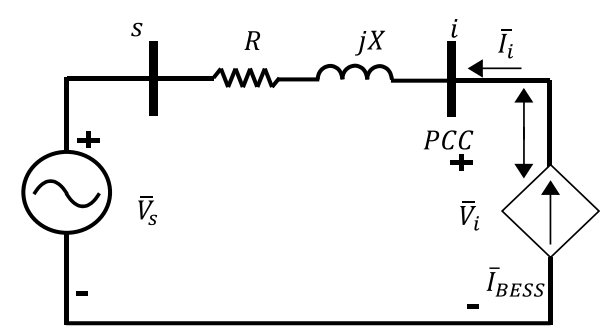

(b)

Figure 1. A BESS feeding into the grid: (a) Components of a BESS and (b) the equivalent circuit of the set-up.

The active power, reactive power, and apparent power the BESS injects at the PCC are $P_{i}, Q_{i}$ and $S_{i}$ respectively. Vector quantities $V_{i}$ and vector $I_{i}$ are the phasor of voltage at the PCC and phasor current injected at the PCC by the BESS, respectively, with the complex conjugates of these quantities given by vectors $V_{i}{ }^{*}$ and $I_{i}{ }^{*}$, respectively. The apparent power injected by the BESS can be written as

$$
\bar{S}_{i}=P_{i}+j Q_{i}=\bar{V}_{i} \cdot \bar{I}_{i}
$$

and the injected current as

$$
\bar{I}_{i}=\left(\frac{\bar{S}_{i}}{\bar{V}_{i}}\right)^{*}=\left(\frac{P_{i}-j Q_{i}}{\bar{V}_{i}^{*}}\right)
$$

Based on the equivalent circuit in Figure $1(\mathrm{~b})$, the voltage at the PCC bus $i$ can be expressed in terms of voltage $\mathrm{V}_{s}$ and voltage change as

$$
\bar{V}_{s}=\bar{V}_{i}-\bar{I}_{i} \bar{Z}
$$

which can and rewritten in terms of $V_{i}$ to obtain

$$
\bar{V}_{i}=\bar{V}_{s}+\bar{I}_{i}(R+j X)=\bar{V}_{s}+\Delta \bar{V}
$$

Solving $\Delta V$ in (4), and substituting (2) in the resultant expression, the outcome is

$$
\Delta \mathrm{V}=V_{i}-V_{s}=\left(\frac{P_{i}-j Q_{i}}{\bar{V}_{i}^{*}}\right)(R+j X)
$$

which leads to

or

$$
\Delta V=\frac{P_{i} * R+Q_{i} * X}{\left|\bar{V}_{i}\right|}+j \frac{P_{i} * X+Q_{i} * R}{\left|\bar{V}_{i}\right|}
$$

$$
\Delta \bar{V}=\left|\Delta \bar{V}_{r e}\right|+j\left|\Delta \bar{V}_{i m}\right|
$$

Since the phase difference between busses $i$ and $s$ is relatively insignificant, the imaginary component of the voltage change is small relative to the real part and can be ignored. With this consideration, the voltage $V_{S}$ can be simplified to 


$$
\left|V_{i}\right|=\left|\bar{V}_{s}\right|+|\Delta \bar{V}|=\left|\bar{V}_{s}\right|+\frac{P_{i} * R+Q_{i} * X}{\left|\bar{V}_{i}\right|}
$$

Equation (8) shows that both the active power $P_{i}$ and reactive power $Q_{i}$ of the BESS can change the voltage at the PCC. Injecting either $P$ or $Q$ increases the voltage, whereas absorption of either quantities by the BESS has the effect of reducing the voltage change. Furthermore, $P$ and $Q$ can be independently controlled, and this enables a 4-quadrant operation. The choice of quadrant of operation depends on the particular application for which the BESS is being utilised.

\subsection{Modes of Operation of a BESS Converter}

This section discusses various modes of BESS operation, including the constant voltage control mode, constant power factor control mode, and constant reactive power mode. For each mode, aspects discussed include a description of the control mode, when is it appropriate to use the mode, and what could be its benefits or adverse effects.

Voltage control in power systems [40] is aimed at keeping voltages at all busses within acceptable limits by controlling the voltage or the reactive power flow. The BESS has the capability for automatic voltage control and reactive power control. These capabilities enable the BESS to regulate voltage levels. Considering these capabilities, the BESS can operate in three modes [41], namely, constant voltage control mode, constant power factor control mode, and constant reactive power mode.

\subsubsection{Constant voltage control mode}

In the constant voltage control mode, the BESS directly controls the voltage at the point of connection by adjusting its reactive power output, i.e., injecting capacity reactive power if voltages are lower or absorbing capacitive reactive power if voltages are higher. The control range is dictated by the reactive power capability of the BESS. The reactive power generated is adjusted on the basis of the deviation of measured voltage from the set point.

\subsubsection{Constant reactive power control mode}

The BESS can operate in constant reactive power control mode so that the control determines and controls the amount of reactive injected into or absorbed from the connection point, following a reactive power generation command.

\subsubsection{Constant power factor control mode}

In the constant reactive power control mode of the BESS, the control directly controls the power factor of the connection point. The reactive power injected into or absorbed from the connection point is a function of the active power generated or consumed by the BESS.

\section{BESS and its Impact on Voltage Sags: Case Studies and Description of Methodology}

To gain insight into how the incorporation of a BESS into the power system affects the voltage sag performance, three case studies are analysed in this paper.

- The first case will assess how incorporating a BESS affects the voltage sags. Here, the magnitudes of voltages for the case with BESS will be compared to the case without BESS. The BESS will be assumed to operate in voltage control mode, and a power factor of 0.9 leading will be assumed.

- In the second case, the impact of the power factor of the BESS converter on voltage sags will be studied. A case of the BESS converter operating at unity power factor will be compared with the converter operating at a leading power factor of 0.9 .

- The final case study will assess and compare the impacts of various BESS convertor control modes on voltage sag performance. The modes of interest will be constant voltage control, constant power factor control, and constant reactive power. 


\subsection{Method of Fault Positions and the Study of Voltage Sag}

From a voltage sag perspective, the performance of a system can be determined by deriving the expected number of voltage sags per annum at a particular node of the system. One way of doing this is by using probabilistic prediction techniques, as opposed to measurements, with the advantages that performance can be estimated and results can be obtained immediately. One of these probabilistic methods is the so-called method of fault positions. Its salient features are as follows [42]:

- A number of equally-spaced, discrete positions along a line in the network are selected.

- At these positions, network faults are simulated and the lowest residual voltages after fault clearances are recorded.

- The expected number of critical voltage sags/annum is then calculated. For example, for single phase to ground faults, equation (9)

$$
N_{1 \phi}=\sum_{i}^{n}\left(l_{i} \cdot \lambda_{q} \cdot p_{1 \phi}\right) \rho_{\operatorname{sag}(i)}
$$

encapsulates the procedure where $N_{1 \phi}$ is the total number of expected critical voltage sags/annum for the system due to single phase to ground faults, $n$ is the total number of lines in the system, $l_{i}$ is the length of a specific line $i, \lambda_{q}$ is the historical number of faults $/ \mathrm{km} / \mathrm{annum}$, $p_{1 \phi}$ is the probability of having a single phase to ground fault, and $\rho_{\text {sag(i) }}$ is the probability of a voltage sag at bus 1 due to a fault on line $i$.

\subsection{Simulating Faults and Generating Voltage Sags}

Four types of faults will be considered in this study, namely single phase to ground faults, phase to phase faults, phase to phase to ground faults, and three phase faults. Faults will be simulated at $5 \%$ intervals of the line length. The approach to fulfil this is as follows [43]:

- Set-up the test network, ensuring correct load-flow data is included and a dynamic representation of the system is appropriate.

- At the discrete positions identified, apply network faults and record the lowest residual voltages after clearance of fault at bus 1 .

- The above steps are repeated for all 672 discrete positions in the lines of the systems.

\subsection{Network and Data}

The single line diagram of the network that is used in this paper is presented in Figure 2. The data of the various components are as follows.

- All lines at $150 \mathrm{kV}$ have a positive (and negative) sequence impedance of $0.097+\mathrm{j} 0.39 \Omega$ per unit $/ \mathrm{km}$, the line charging of $0.010000 S$ per unit $/ \mathrm{km}$, and zero sequence impedance of $0.497+$ $\mathrm{j} 2.349 \Omega$ per unit $/ \mathrm{km}$.

- The length of lines 1-2, 2-3, and 3-4 is $10 \mathrm{~km}$ and the parameters of these lines are as follows: the positive (and negative) sequence impedance is $0.22+\mathrm{j} 0.37 \Omega$ per unit $/ \mathrm{km}$, the line charging is $0.003000 S$ per unit $/ \mathrm{km}$, and the zero-sequence impedance is $0.37+\mathrm{j} 1.56 \Omega$ per unit $/ \mathrm{km}$.

- The length of lines 2-5 and 3-6 at $20 \mathrm{kV}$ is $10 \mathrm{~km}$. The parameters are a positive (and negative) sequence impedance of $1.26+\mathrm{j} 0 . \Omega$ per unit $/ \mathrm{km}$, the line charging of $0.001000 \mathrm{~S}$ per unit $/ \mathrm{km}$, and the zero-sequence impedance of $1.37+\mathrm{j} 1.067 \Omega$ per unit $/ \mathrm{km}$.

- $\quad$ The size of all the loads is $1.07 \mathrm{MW}+\mathrm{j} 0.1 \mathrm{Mvar}$. The power generated at bus 9 is $3 \mathrm{MW}+\mathrm{j} 3.8$ Mvar. Bus 8 is the swing bus of the system. 


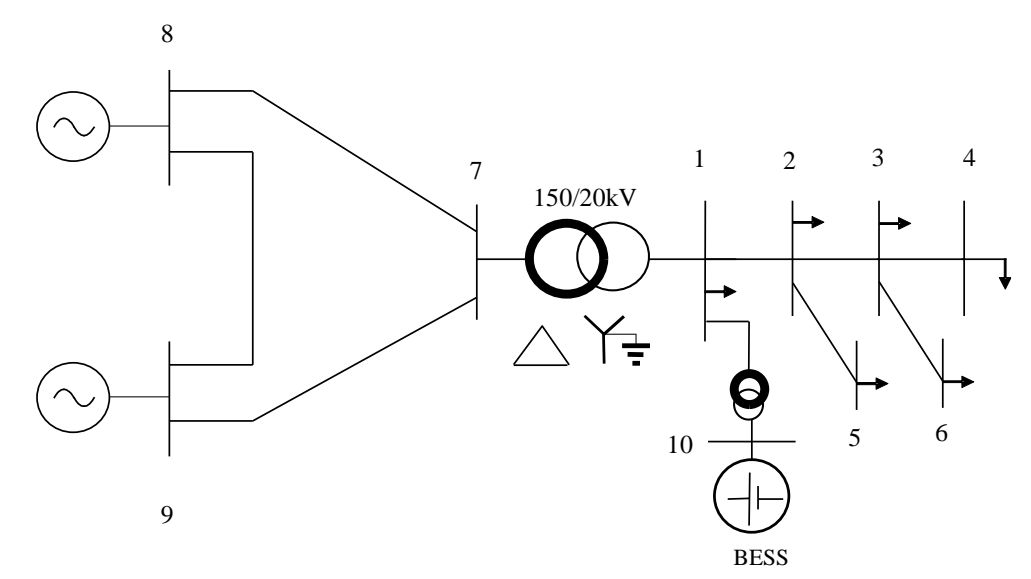

Figure 2. Single line representation of the network used in the study [42].

\subsection{Rates of Line Faults and Probability of Fault Types [42]}

For the purpose of calculating the number of faults per annum occurring on the lines, it is assumed that one (1) fault $/ \mathrm{km} /$ annum occurs for $20 \mathrm{kV}$ lines and 0.1 fault $/ \mathrm{km} / \mathrm{annum}$ occurs for 150 $\mathrm{kV}$ lines. Furthermore, it is assumed that the probabilities of occurrence for phase to ground faults, phase to ground faults, phase to phase to ground faults, and phase to phase faults are as are $0.8,0.07$, 0.07 , and 0.06 , respectively, for $150 \mathrm{kV}$ lines. For the $20 \mathrm{kV}$ level, the corresponding probabilities are $0.65,0.17,0.08$, and 0.1 .

\subsection{Modelling of the BESS in PSS/E using the WECC model}

To simulate faults and observe voltage sags, the Power System Simulator for Engineering (PSS/E) Software [44] is utilised. The software comprises a suite of programs for power system analysis. For the studies done, the BESS is connected to the network at bus 1, via a step-up transformer, which has a lower voltage at bus 10. The key details for modelling the BESS and its transformer are described below.

\subsubsection{Steady state modelling of the BESS}

The BESS is assumed to have a -1.5 to $+1.5 M W$ and -1.125 to +1.125 Mvar capability, i.e., a lowest power factor of \pm 0.9 is assumed. The BESS is modelled as a wind machine with specified reactive power limits and with a high impedance [45], as required in the PSS/E software.

\subsubsection{Dynamic modelling: cons, icons, vars}

In this work, the Western Coordinating Council (WECC) model [46] for representing the behaviour of BESS dynamics is used. The dynamic model comprises three components:

- Plant controller module (REPC_A). This model processes the frequency and active power output of the BESS to match frequency or active power control. It also processes voltage and reactive power output of the BESS to match volt/var control at the plant level. The output of the REPC_A provides active and reactive power command input to the electrical control module.

- $\quad$ Electrical control module (REEC_C). This module acts on active and reactive power references from the plant controller module, with feedback of terminal voltage for specification of a prescribed reactive control response during voltage dips. This module provides real and reactive current commands to the generator/converter module.

- Generator/converter module (REGC_A). This processes real and reactive current commands from the electrical control module, with feedback of terminal voltage for lower voltage active current and high voltage reactive current management logics, and outputs real and reactive current injections into the network model. 
The data related to the components above are classified into icons, cons and vars in PSS/E dynamic models. The icons class gathers all data, e.g., constant and parameters, of the controllers. In the cons class, the data that can be configured to set the mode of operation of the converter are kept. The vars data selects the signals of the BESS to be recorded during the run of the dynamics simulation.

\subsection{Transformer Modelling Details}

The BESS is connected to the network via a step-up transformer. The reactance of the transformer is $5 \%$ per unit and a delta and grounded star winding arrangements for the network and the BESS side, respectively, are selected.

\section{Results and Discussion}

\subsection{Impact of BESS on Voltage Sags}

\subsubsection{Post-Fault Residual Voltage}

Figure 3 shows the residual voltages recorded at the monitoring bus 1, following disturbances, for the case without and with the BESS. The results demonstrate that the magnitudes of recorded remaining voltages for the case with the BESS integrated into the system are higher than for the case without BESS.



Fault Location (\% Line Length)

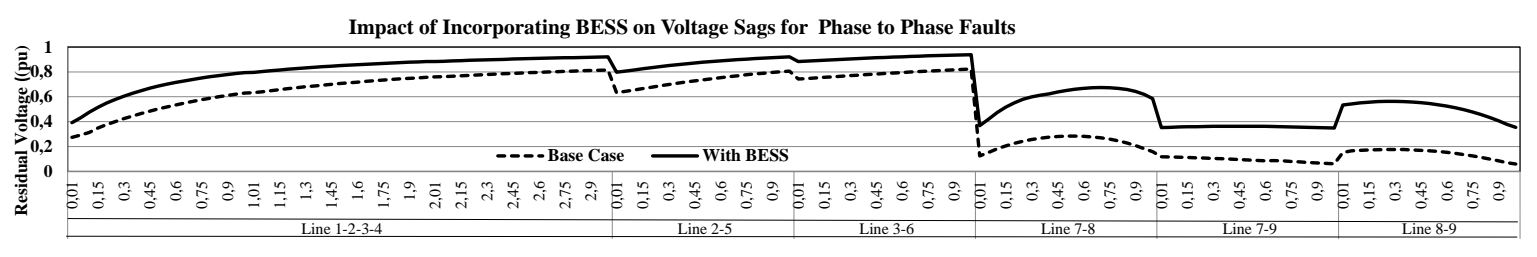

Fault Location (\% Line Length)

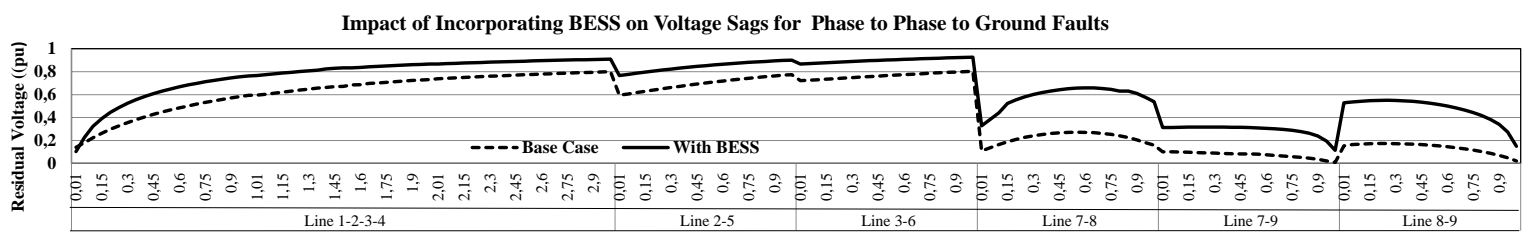

Fault Location (\% Line Length)

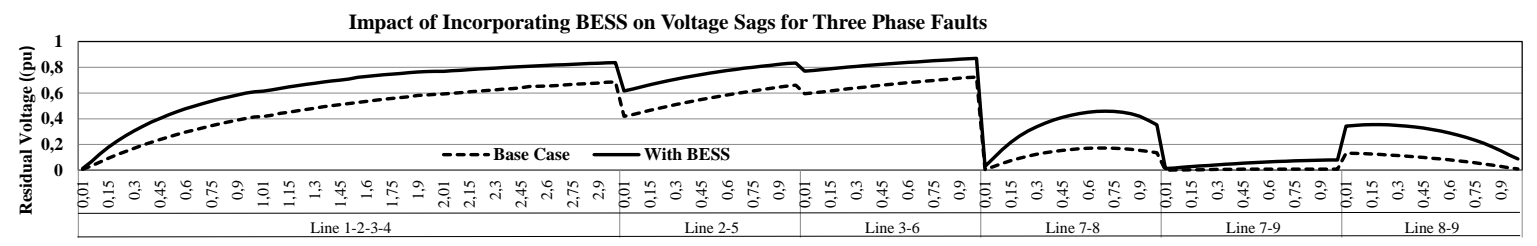

Fault Location (\% Line Length)

Figure 3. Residual voltages at bus 1 for the case without and with BESS. 


\subsubsection{Observed number of Voltage Sags}

The residual voltages in Figure 3 are further summarised in various ranges of voltages in Figure 4. In the presence of a BESS, the number of voltages in the higher windows increases appreciably, as can be seen by the higher number of observations in the 0.8-0.9 and $>0.9$ ranges. Furthermore, there are 149 observations in the $>0.9$ range for the case with the BESS compared to the base case (26 observations). This means that a substantial number of observations that would have been classified as sags in cases without BESS are now no longer suitable for that category. The BESS thus appears to ameliorate the severity of voltages sags or results in some of the sags being eliminated entirely.

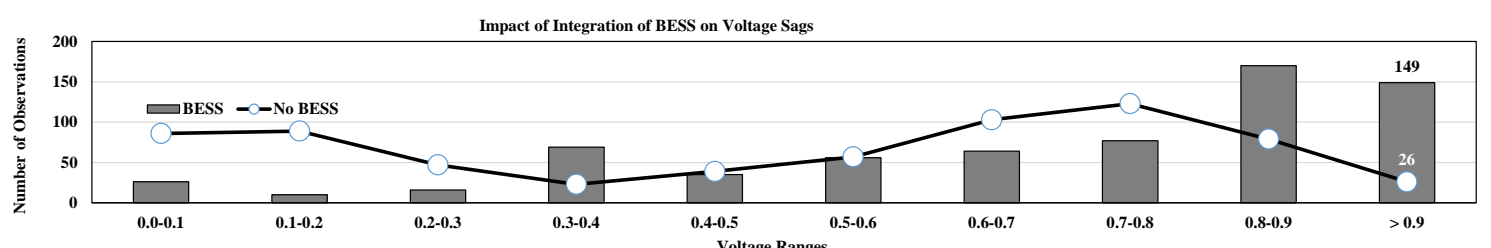

Figure 4. Number of residual voltages observed in various windows for the case without and with BESS.

\subsubsection{Expected Number of Critical Voltage Sags}

The expected number of voltage sags for various voltage sensitivity criteria and fault types are summarised in Figure 5. The results demonstrate that the expected number of voltage sags is always lower for the case with BESS compared to the case without.
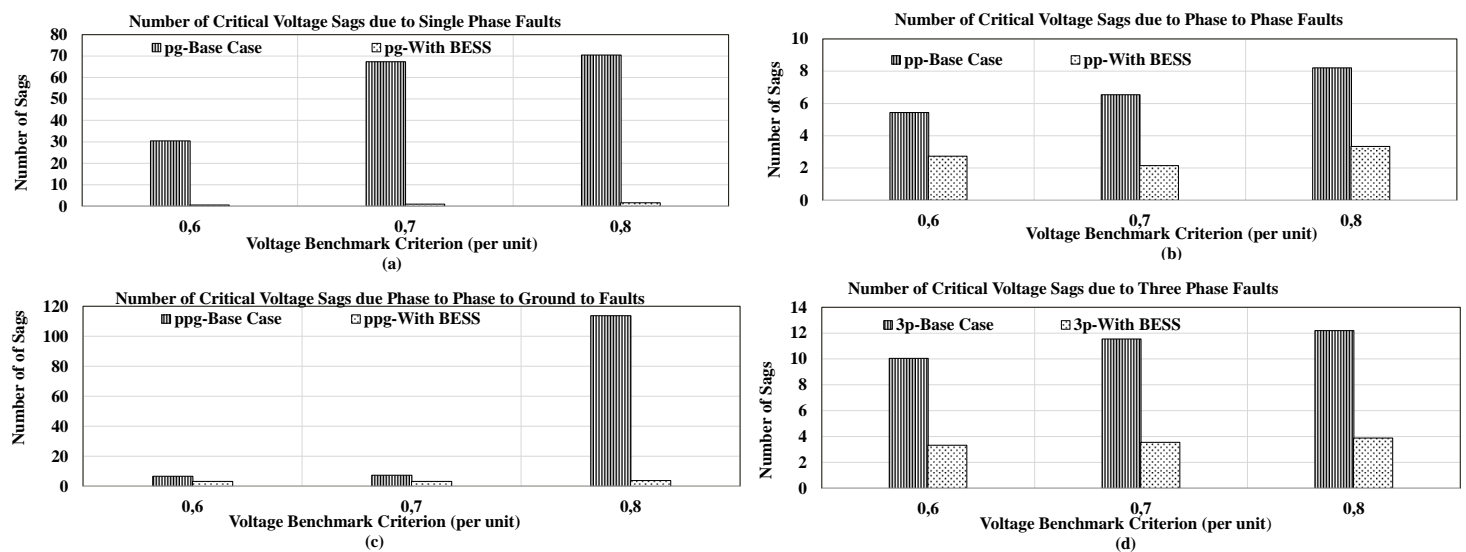

Figure 5. Expected number of critical sags for the case without and with BESS.

\subsection{Impact of BESS Converter Power Factor on Voltage Sags}

\subsubsection{Post-Fault Residual Voltages}

The results of the study of the impact of the power factor of the BESS converter on voltages sags are presented in Figure 6, which presents the residual voltages at bus 1 following faults. The cases assessed are the converter operating at power factors of 1 and 0.9 leading. Higher, i.e., better recorded residual voltages are obtained with the lower power factor of 0.9 leading. 


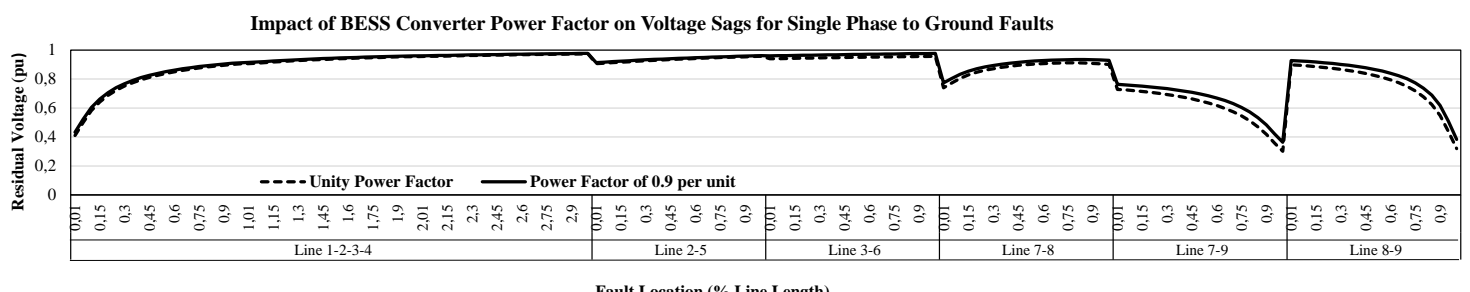

Fault Location (\% Line Length)

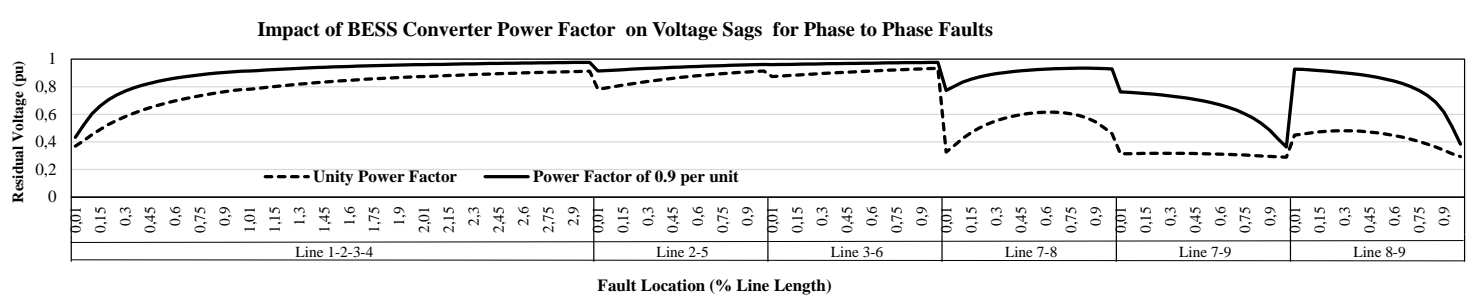

Impact of BESS Converter Power Factor on Voltage Sags for Phase to Phase to Ground Faults

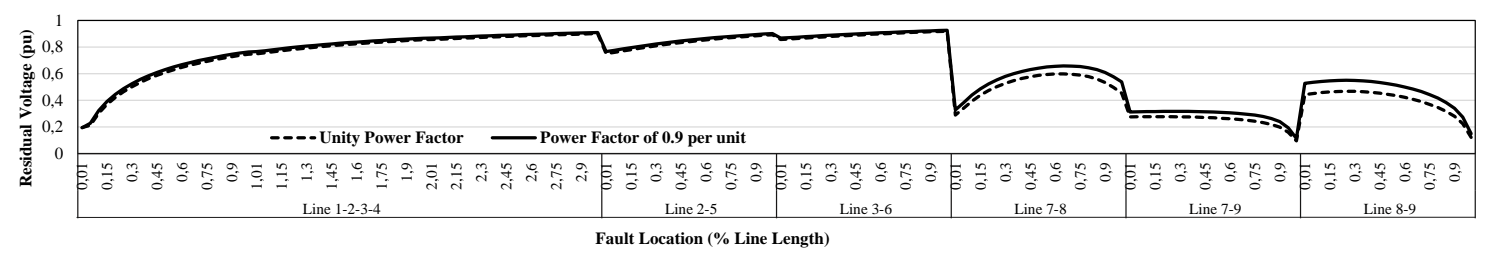

Impact of BESS Converter Power Factor on Voltage Sags for Three Phase Faults

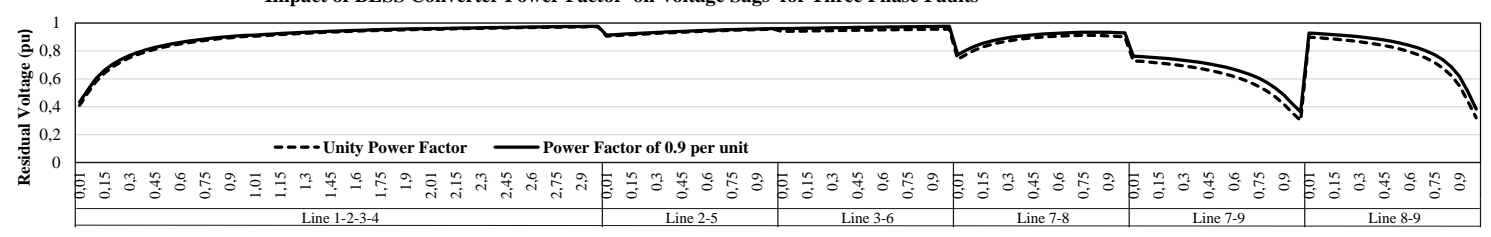

Fault Location (\% Line Length)

Figure 6. Residual voltages at bus 1 for BESS power factors of unity and 0.9 per unit.

\subsubsection{Observed Number of Voltage Sags}

The residual voltages in Figure 6 are again summarised in Figure 7 to present the number of residual voltage observations in various voltage windows. When the BESS is incorporated, the number of observations in the higher voltage windows tend to be higher than otherwise. Furthermore, about 30 more observations become classified as non-voltage sags in the presence of the BESS.

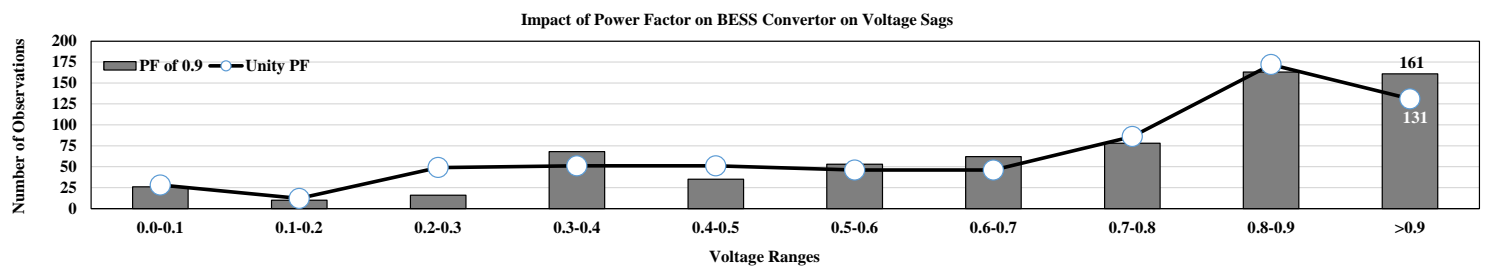

Figure 7. Number of residual voltages in various windows for BESS power factors of unity and 0.9 per unit.

\subsubsection{Expected Number of Critical Voltage Sags}

Figure 8 summarises the number of expected voltage sags for various fault types and various voltage level benchmarks. The results show that the expected number of voltage sags reduced appreciably for the case of a BESS operating at a lower power factor. 



Figure 8. Expected number of critical voltage sags for BESS power factors of unity and 0.9 per unit.

\subsection{Impact of BESS Converter Control Mode on Voltage Sags}

\subsubsection{Post-Fault Residual Voltages}

The magnitudes of residual voltages recorded at the monitoring bus 1 for the constant voltage, constant power factor and constant reactive power control modes of the BESS converter are presented in Figure 9. The recorded voltages for the constant power factor and constant reactive power controller modes are identical. The residual voltages recorded for the constant voltage control mode are generally higher than those for the two other control modes of the BESS converter.

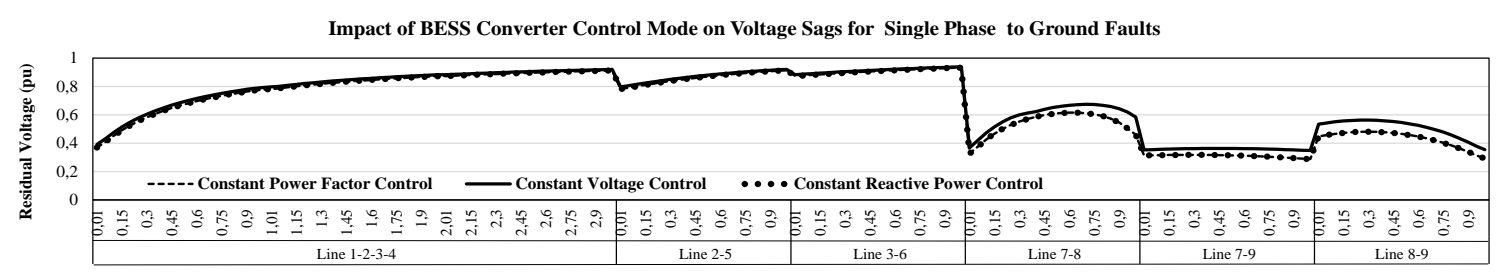

Fault Location (\% Line Length)

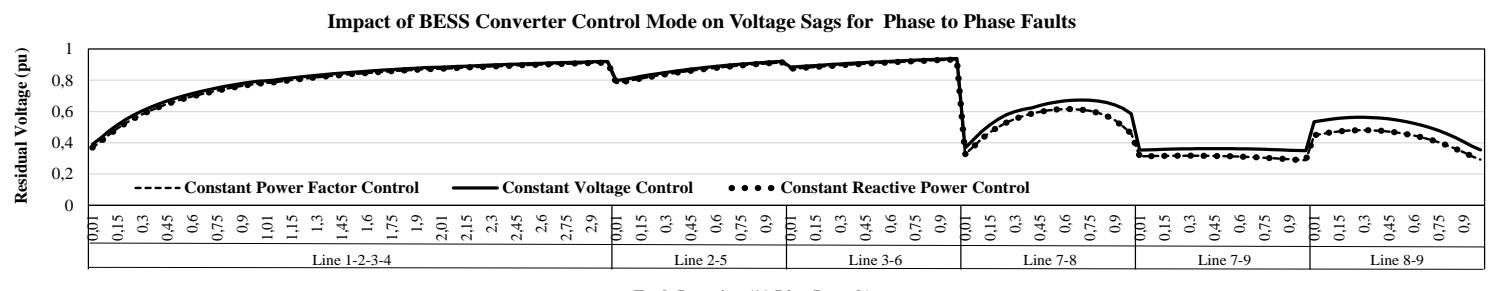

Fault Location (\% Line Length)
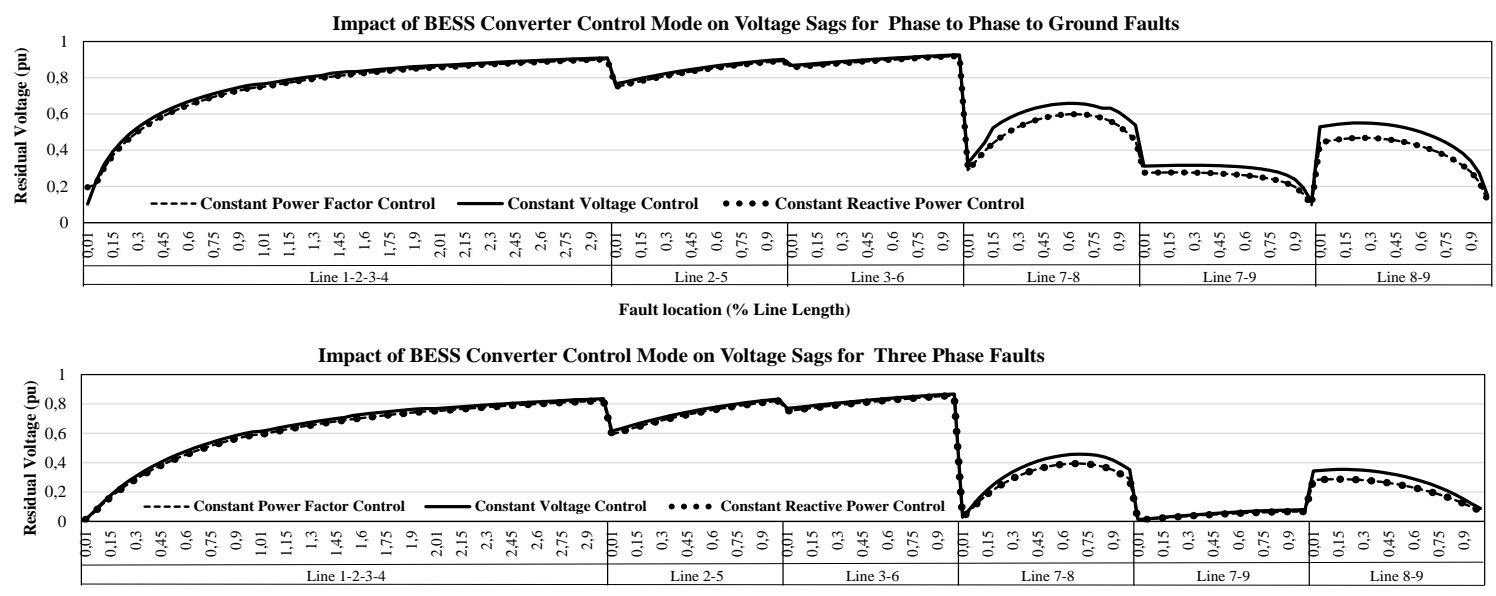

Fault Location (\% Line Length)

Figure 9. Residual voltages at bus 1 for various BESS inverter control modes. 


\subsubsection{Number of Observed Voltage Sags}

Figure 10 summarises the number of recorded voltages for various ranges. Firstly, the graph shows that the profile of observations is virtually the same for the constant power and constant $Q$ control modes. The second observation is that the number of observations in the lower voltage ranges, i.e., ranges below 0.8-0.9 range, is lower for the voltage control mode compared with the other two modes. However, observations of voltages greater in the 0.8-0.9 and greater than the 0.9 ranges are higher for the voltage control mode. This suggests that with the voltage control mode, potential voltage sags are at largely ameliorated. Also, a large number of potential voltage sags is eliminated as non-voltage sag observations increase noticeably with constant voltage control mode.

\subsubsection{Expected Number of Critical Voltage Sags}

The expected number of critical voltage sags for various fault types for various modes of BESS control, are presented in Figure 11. The first observations are that the expected number of critical voltage sags for various voltage sensitivity criteria are the same for the constant power factor and constant reactive power converter control modes. In the second instance, far fewer numbers of expected voltage sags are realised with the constant voltage control mode of the BESS inverter.

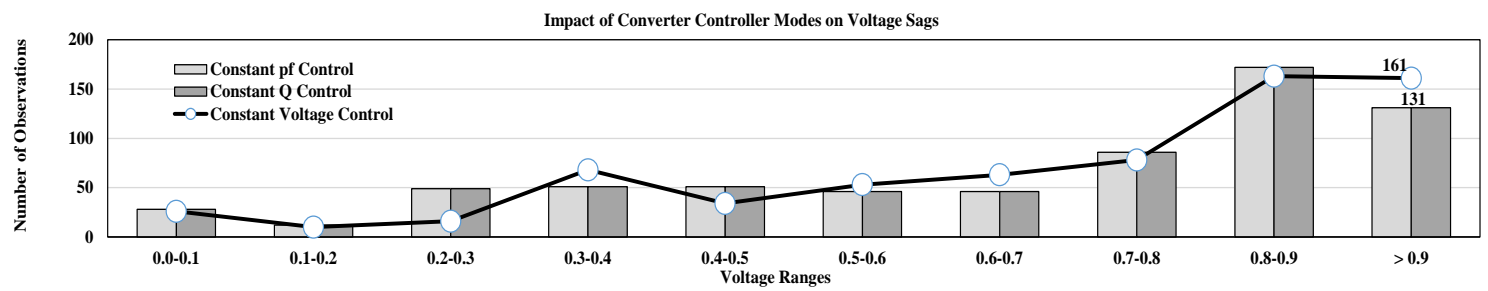

Figure 10. Residual voltages observed in various windows for various control modes of the BESS converter.
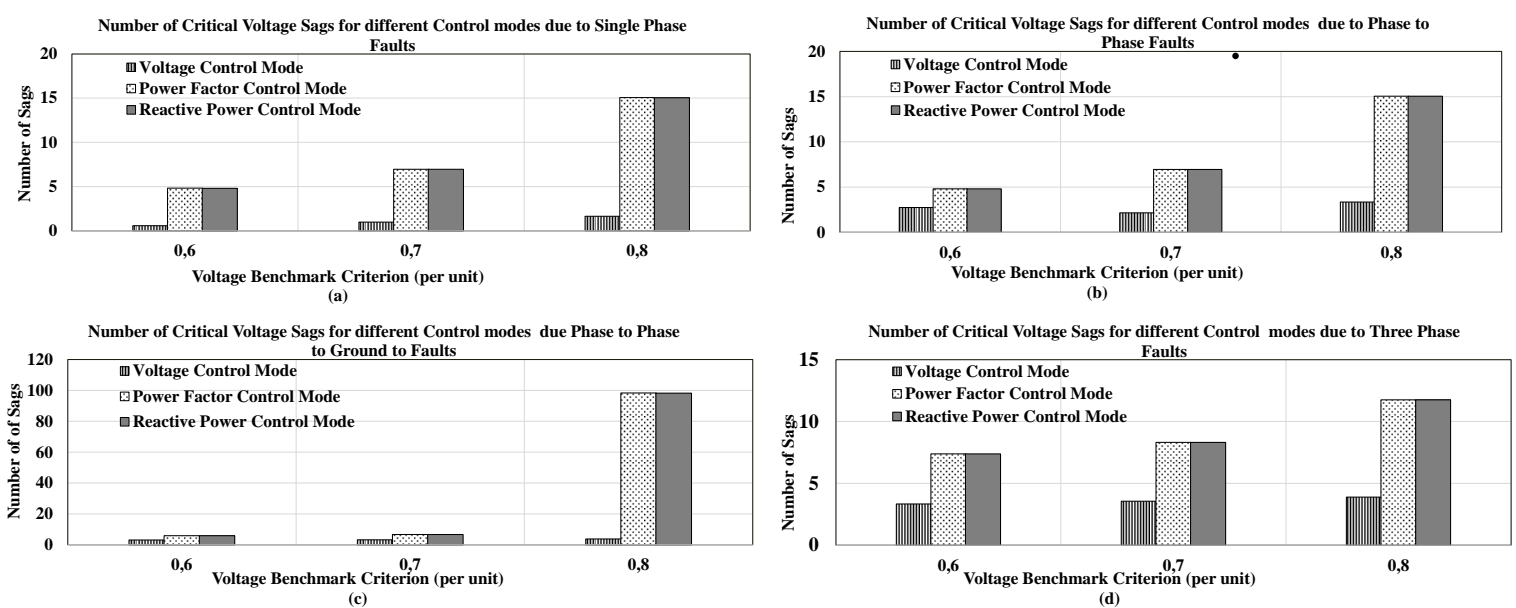

Figure 11. Expected number of critical voltage sags for various BESS converter control modes.

\section{Conclusions}

In this paper, the authors present the impact of the battery energy storage system (BESS) on voltage sags as found during their research. Firstly, with the BESS integrated into the network, results showed higher residual voltages, fewer voltage sags and lower expected critical voltage loss. Secondly, when the BESS converter power factor was reduced, recorded residual voltages were higher, voltage sags were less frequent, and the number of expected critical voltage sags was lower.

Finally, when three BESS converter control modes, namely constant voltage, constant power factor, and constant reactive power, were assessed, similar voltage sag performances for constant power factor and constant reactive power modes resulted. Furthermore, operating in constant voltage control outperformed the voltage sag performance of the other two modes as it delivered higher residual voltages, a lower number of voltage sags, and fewer expected critical voltage sags. 
The work presented in this paper provides another demonstration that a BESS can improve quality of supply, in general, and voltage sag performance, in particular. Furthermore, the study gives insights into how various BESS converter control modes compare on the basis of voltage sag performance.

Author Contributions: A collaborative effort by the authors made the production of this manuscript possible. Nhlanhla Mbuli developed the idea of this research and guided the various phases of the research. Sebu Lichaba did literature reviews and carried out simulations. Ronald Xezile provided technical support on running the simulations in PSS/E and Jan-Harm Pretorius provided oversight over the research and gave guidance to the team.

Acknowledgments: The authors wish to express their gratitude to Eskom Holdings SoC and University of Johannesburg, both in South Africa, for providing the resources and facilities required to complete this research project.

Conflicts of Interest: The authors declare no conflict of interest.

\section{References}

1. Medina, P.; Bizuayehu, A. W.; Catalão, J.P.S.; Rodrigues, E.M.G.; Contreras, J. Electrical energy storage systems: Technologies' state-of-the art. Techno-Economic Benefits and Applications Analysis. In Proceedings of the 47th Hawaii International Conference on System Science, Waikoloa, Hawaii, United States of America, 6-9 January 2014; pp. 2295-2304.

2. Carnegie, R.; Gotham, D.; Nderitu, D.; Preckel, P.V. State Utility Forecasting Group, Utility scale energy storage systems. Benefits, Applications, and Technologies, June 2013.

3. Bhandari, B.; Poudel, S.R.; Lee, K.; Ahn, S. Internal mathematical modeling of hybrid renewable energy, system: A review on small hydro-solar-wind power generation. Journal of Precision Engineering and Manufacturing - Green Technology April 2014, Vol. 1, No. 2; pp. 157-173.

4. Desideri, U.; Campana, P.E. Analysis and comparison between a concentrating solar and a photovoltaic power plant; Applied Energy 2014, Vol. 113, pp. 422-433.

5. World Energy Council. Variable renewables integration in electricity systems: How to get it right; World Energy Perspectives: Renewables Integration 2016.

6. Renewables 2019. Global Status Report. Available online: https://www.ren21.net/reports/global-statusreport/ (accessed on 3 July 2020).

7. Global Energy Systems based on $100 \%$ Renewables-Power Sector. Available online: https://www.google.co.za/search?q=drivers+for+global+electricity+demand+pdf\&ei=7MUKXbj7446Y1fAP 5LWrqA0\&start=10\&sa=N\&ved=0ahUKEwi4odmU2vbiAhUOTBUIHeTaCtUQ8tMDCJkB\&biw=1138\&bi

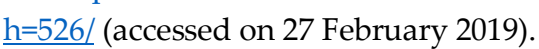

8. Mueller, S.; de Sisternes, F.; Patriarca, E.; Portellano, A.; Goeritz, A.; Moller, J.D.; Peter, J.; Holttinen, H. The power of transformation - wind, sun and the economics of flexible power systems. Paris, 2014.

9. Alshahrani, A.; Omer, S.; Su, Y.; Mohamed, E.; Alotaibi, S. The technical challenges facing the integration of small-scale and large-scale PV systems into the grid: A critical review. Electronics 2019, Vol. 8, pp. 1-28.

10. Chang, W. A literature review of wind forecasting methods. Journal of Power and Energy Engineering 2014, Vol. 2, pp. 161-168.

11. Sinsel, S.; Riemke, R.; Hoffmann, V. Challenges and solution technologies for the integration of variable renewable energy sources - a review. Renewable Energy 2019, Vol. 145, pp. 2271-2285, doi.org/10.1016/j.renene.2019.06.147.

12. Lopes, J.A.P; Hatziargyriou, N.; Mutale, J.; Djapic, P.; Jenkins, N. Integrating distributed generation into electric power systems: A review of drivers, challenges and opportunities. Electric Power Systems Research 2007, Vol. 77, pp. 1189-1203.

13. Zhang, C.; Wei, Y.; Cao, P.; Lin, M. Energy storage system: Current studies on batteries and power condition system. Renewable and Sustainable Energy Reviews 2018, Vol. 82, pp. 3091-3106.

14. Xu, X.; Bishop, M.; Oikarinen, D.G.; Hao, C. Application and modeling of battery energy storage in power systems. CSEE Journal of Power and Energy Systems September 2016, Vol. 2, No. 3, pp. 82-90.

15. IRENA, Innovation landscape brief: Utility-scale batteries, International Renewable Energy Agency, Abu Dhabi, 2019. Available online: 
https://www.irena.org/documentdownloads/publications/irena_battery_storage_report_2015.pdf (accessed on 22 August 2020).

16. Eyer, J.; Corey, G. Energy storage for the electricity grid: benefits and market potential assessment guide, A study for the DOE Energy Storage Systems Program, SANDIA Report February 2010, SAND2010-0815, Unlimited Release.

17. EPRI-DOE, Handbook of energy storage for transmission and distribution applications; 1001834, Final Report December 2003.

18. Akhil, A.; Huff, G.; Currier, A.B.; Kaun, B.C.; Rastler, D.M.; Chen, S.B.; Cotter, A.L.; Bradshaw, D.T.; Gauntlett, W.D. DOE/EPRI Electricity Storage Handbook January 2015, in Collaboration with NRECA SANDIA Report, SAND2015-XXX, Supersedes SAND2013-5131, Unlimited Release.

19. Yan, T.; Qu, Z.Z.; Jia, P.Y.; Liu, Y.J.; Hu J.; Hui, D. Lai, X.K. The research of voltage flicker detection based on IRPT and mitigation based on BESS. In Proceedings of the International Conference on Computer Information Systems and Industrial Applications, Beijing, China, 2015; pp. 931-934.

20. Cifuentes, N.; Rahmann, C.; Valencia, F.; Alvarez, R. Network allocation of BESS with voltage support capability for improving the stability of power systems. The Institute of Engineering and Technology 2019, Vol. 13, No. 6, pp. 939-949.

21. Ahmed, H.M.A.; Awad, A.S.A.; Ahmed, M.H.; Salama, M.M.A. Mitigating voltage-sag and voltagedeviation problems in distribution networks using battery energy storage systems. Electric Power Systems Research 2020, Vol. 184, pp. 106-294.

22. Tant, J.; Geth, F.; Six, D.; Tant, P.; Driesen, J. Multiobjective battery storage to improve PV integration in residential distribution grids. IEEE Transactions on Sustainable Energy January 2013, Vol. 4, No.1, pp. 182191.

23. Rouco, L.; Sigrist, L. Active and reactive power control of battery energy storage systems in weak grids. In Proceedings of 2013 IREP Symposium Bulk Power System Dynamics and Control - IX Optimization, Security and Control of the Emerging Power Grid Madrid, Spain, 25-30 August 2013; pp. 1-7.

24. Rabbi, A.E.; Arif, S.; Avis, T. Performance comparison of STATCOM and BESS for restoring voltage under post fault scenario. In Proceedings of the 2019 IEEE Region 10 Symposium, Kolkata, India, 7-9 June 2019, pp. 435-440.

25. Jamroen, C.; Pannawan, A.; Sirisukprasert, S. Battery energy storage system control for voltage regulation in microgrid with high penetration of PV generation. In Proceedings of the 53rd International Universities Power Engineering Conference. Glasgow, UK, 4-7 September 2018; pp. 1-6.

26. Zeraati, M.; Golshan, M.E.H. Distributed control of battery energy storage systems for voltage regulation in distribution networks with high PV penetration. IEEE Transactions on Smart Grids 2018, Vol. 9, No. 4, pp. 3582-3593.

27. Arduini, F.R.; Martinus, D.B.; Junior, B.R.P; Asada, E.N. BESS Support to DFIG-based wind turbines connected to medium-voltage distribution networks. In Proceedings of the 2019 IEEE PES Innovative Smart Grid Technologies Conference - Latin America, Gramado, Brazil, 15 - 18 September 2019; pp. 1-6 .

28. Kawabe, K.; Yokoyama, A. Study on short-term voltage stability improvement using batteries on extrahigh voltage networks. In Proceedings of the 2013 IEEE Grenoble Conference, Grenoble, France, 16 - 20 June 2013; pp.1-3.

29. dos Santos Pereira, G.M.; Tabata, A.N.; Lachovics, F.J.; Durce, C.C.; Kowaltschuk, R. Electrical power quality analysis of under voltage load shedding with a battery energy storage system support in the Brazilian context. In Proceedings of the 2018 IEEE 9th Power, Instrumentation and Measurement Meeting, Salto, Uruguay,14-16 November 2018; pp. 1-6.

30. Yang, Z.; Shen, C.; Zhang, L.; Crow, M.L.; Atcitty, S. Integration of a StatCom and Battery Energy Storage. IEEE Transactions on Power Systems May 2001, Vol. 16, No. 2, pp. 254-270.

31. Ghorbanian, M.J.; Goodarzvand, F.; Poudaryaei, A.; Mahadi, W.N.L. Power quality improvement of grid connected doubly fed induction generator using STATCOM and BESS. In Proceedings of the 2014 th International Conference on Engineering Technology and Technopreneurship, Kuala Lumpur, Malaysia, 27 -29 August 2014; pp. 110-115.

32. Liu, J.; Su, C.; Wang, X.; Fang, W.; Niu, S.; Cheng, L. Abnormality in power system transient stability control of BESS/STATCOM. The Journal of Engineering 2017, Vol. 2017, No.13, pp. 1040-1044. 
33. Kanchanaharuthai, A.; Changkong, V.; Loparo, K.A. Transient stability and voltage regulation in multimachine power systems vis-à-vis STATCOM and battery energy storage. IEEE Transactions on Power Systems 2015, Vol. 30, No. 5, pp. 2404-2415.

34. Menaneanatra, T.; Chattranont, N.; Wanchana, S.; Kaewmanee, J. Voltage sag ride through of distribution grid-connected wind energy system with D-STATCOM. In Proceedings of CIGRE AORC 2011, Bangkok, Thailand, 26-28 October 2011, pp. 1-20.

35. Virulkar, V.B.; Aware, M.V. Reactive and real power compensation with DSTATCOM and BESS for mitigation of flicker. Int. J. Power and Energy Conversion 2009, Vol. 1, No. 4, pp. 384-398

36. Bollen, M.H.J. Understanding power quality problems: Voltage sags and interruptions. IEEE Press Series on Power Engineering, The IEEE, Inc., New York: USA, 2000.

37. Wolf, A.; Wenzel, L. Regional diversity in the costs of electricity outages: Results for German Counties. Utilities Policy 2016, Vol. 43, pp. 195-205.

38. Lawder, M.T.; Suthar, B.; Northrop, P, W.; De, S.; Hoff, C.M.; Leitermann, O.; Crow, M. L.; Santhanagopalan, S.; Subramanian, V.R. Battery energy storage system (BESS) and battery management system (BMS) for grid-scale applications. Proceedings of the IEEE June 2014, Vol. 102, No. 6, pp. 1014-1030.

39. Xie, B.; Liu, Y.; Ji, Y.; Wang, J. Two-stage battery energy storage system (BESS) in AC microgrids with balanced state-of-charge and guaranteed small-signal stability. Energies 2018, Vol. 11, No. 322, pp. 1-14.

40. Viawan, F.A.; Karlsson, D. Voltage and reactive power control in systems with synchronous machine-based distributed generation. IEEE Transactions on Power Delivery April 2008, Vol. 23, No. 2, pp. 1079-1087.

41. FINGRID, Grid Code Specifications for Grid Energy Storage Systems SJV201928, February 2020.

42. Mbuli, N.; Xezile, R.; Pretorius, J.H.C. Stochastic assessment of the impact of distributed synchronous generators on voltage sags due to system-wide faults, SAIEE Africa Research Journal June 2020, Vol. 111, No. 2, pp. 65-72.

43. Mbuli, N.; Xezile, R.; Pretorius, J.H.C.; Sowa, P. Evaluation of the impact of distributed synchronous generation on the stochastic estimation of financial costs of voltage sags, Journal of Energy in Southern Africa February 2016, Vol. 27, No. 1, pp. 11-19.

44. PSS/E, Power system simulator for engineering: Online Documentation: Ver. 33.4 (Siemens Energy, Inc., 2013).

45. PSS/E. Program Operation Manual. Siemens Energy, Inc., 2013.

46. S\&C Electric Company, Instructions on Modeling the S\&C Purewave SMS (Storage Management System) Using WECC Generic Battery Energy Storage Model, April 2016. 